\title{
A Corpus-based Analysis of Multimodal Metaphor in Chinese Ecological Educational Advertisements
}

\author{
Liu Qiushi \\ English Language and Literature, The School of Translation Studies, Shandong University, Weihai, China \\ Email address: \\ liuqiushisdu@mail.sdu.edu.cn

\section{To cite this article:} \\ Liu Qiushi. A Corpus-based Analysis of Multimodal Metaphor in Chinese Ecological Educational Advertisements. International Journal of \\ Language and Linguistics. Vol. 8, No. 2, 2020, pp. 60-68. doi: 10.11648/j.ij11.20200802.11
}

Received: February 18, 2020; Accepted: March 10, 2020; Published: March 24, 2020

\begin{abstract}
With the development of technology and the extension to multimodality in linguistics, technology tools get more applied to linguistic study. It is recognized that metaphor should not be trapped in language, but expanded to various mode. Based on the multimedia corpus built by the multimedia annotator software ELAN which gives rise to a more detailed interpretation, this article attempts to explore mysteries in multimodal metaphor in Chinese ecological educational advertisements: what are prominent metaphors characterize this typical advertisement, how modes collaborate in multimodal metaphor, and how meaning creation is processed in multi-mode way. It is classified that four kinds of metaphors are prominently represented, that is, ontological metaphor, color metaphor, money metaphor, and BIG IS SIGNIFICANT. Various modes collaborate simultaneously to construct meaning, and it is suggested that in various modes, there exists differentiation between priority and the others. The more information a mode carries, the more significant it is in collaborations. The most efficient way of TV educational advertisements to convey meaning is visualization, so most of the time the visual mode acts as the priority in assistance with the others. Through simultaneous cueing -- saliently representing target and source domain simultaneously, and perceptual resemblance--the resemblance experienced through visual perception or auditory sense triggers similarity of the source and the target domain, meaning is created and conveyed to audiences.
\end{abstract}

Keywords: Multimodal Metaphor, ELAN, Chinese Ecological Educational Advertisements

\section{Introduction}

Metaphor, traditionally viewed as one figure of speech, is proved a powerful cognitive tool for our conceptualization of the world, and is "not just in language but in thought and action, and our ordinary conceptual system, in terms of which we both think and act, is fundamentally metaphorical in nature" [1]. It is concluded that metaphor does not only occur in written language but also in other modes. Here emerges multimodal metaphor.

Since the first TV educational advertisement of "saving water" was published in 1986, modern China has enjoyed public educational communication through educational advertisements. In modern society, the problem of environment still concerns all human beings, so Chinese government has paid much attention to environmental protection, including the publication of ecological educational advertisements. Given the current situations, there is promising value researching unknown metaphor mysteries and studying common laws in meaning creation of educational advertisements. This study picks CCTV (China Central Television), the Chinese national television station with representativeness and authority, as the source of its corpora. Typically, the corpus consists of thirteen ecological public service advertisements screened on CCTV, four hundred and sixty-five seconds totally.

In order to illustrate the collaboration of modes and meaning creation of multimodal metaphor, the discussion is constructed with three parts: main metaphors in ecological educational advertisements, collaborations of modes, as well as meaning creation of multimodal metaphors. The questions, which this thesis is supposed to resolve, are concerned about multimodal metaphors and modes. As it is shown, from mono-modal to multimodal metaphor, the most significant factor is mode, which differs the ways of metaphorical representations from the traditional one. The first division makes a classification of multimodal metaphors, in which several typical cases are exposed to explain. Following 
discussions on collaborations of modes, meaning creation in multimodal metaphor is discussed as a significant part.

\section{Literature Review}

Linguistic studies on multimodality are currently on two views, multimodal discourse analysis from the perspective of system-functional linguistics and multimodal metaphors from that of cognitive linguistics. In the field of system-functional analysis, following O'Toole's Language of Displayed Art [2] and Kress and Van Leeuwen's Reading Images: The Grammar of Visual Design [3], interest in the use of SF theory for multimodal discourse analysis has steadily increased [4-9]. Among them, O'Halloran [10] claimed a systemic functional (SF) approach to multimodal discourse analysis (MDA) to analyze meaning arising from the use of multiple semiotic resources in multimodal discourses, which also involves the use of digital technology in the form of image-editing software. In terms of cognitive linguistic development, studies on multimodal metaphor take the majority of all. In multimodal metaphor, researchers have widely investigated multimodal metaphors in advertisements, brand image, political cartoons, comics, manga, film, and animation, as well as metaphor in spoken language and co-speech gesture, metaphor in music and sound [11-18].

Multimodal practices emerge in research on TV advertisements. As a special carrier of intention, advertisement has been the subject of a number of studies pertaining to pictorial metaphor -- the variety of non-verbal metaphor that has attracted most scholarly attention. While researchers focus on text-image static advertisements in print media [13, 19-21], dynamic commercial or educational advertisements get no due attention. Among those researches on dynamic corpora in a decided minority, Forceville [14] analyzes multimodal metaphors in ten Dutch TV commercials. He found that TV commercials are unfold with time, so the targets and the sources can be presented successively, and not limited within visual and language mode, but in music or else. Besides, the connection between the target and the source is always highlighted by shots and scenes. However, few researchers provide an integrative or strongly-explanatory theory and frame, leaving multimodal metaphor still a new disciplinary field that does not have a ripe theory and system.

As an initiative pioneer in multimodal metaphorical theory, Forceville [22] has discussed the issues including the proposal to distinguish between mono-modal and multimodal metaphor; reflections on the difference between structural and creative metaphors; the question of how verbalizations of non-verbal or conceptual metaphors may affect their possible interpretation; and thoughts as to how similarity between target and source is created. Scholars have revealed the possible relations between multimodal metaphors and cultural background, metonymy, genre, etc.

As another conceptual device, metonymy has close relation to metaphor, both are always discussed together. Thus, some researchers also discuss the interaction of multimodal metaphor and metonymy in multimedia video or commercial. Urios-Aparisi [23] studies interaction of multimodal metaphor and metonymy in four cases of TV commercial and briefly concludes that layering of rhetorical figures is not random, but follows clear cognitive patterns which restrict and define their design and persuasion. Sometimes, metonymy represents the target for metaphor in a way that can be realistic for the metaphorical representation, and motivate the message of the commercial [23]. This raises thinking about the deeper relations of metonymy and metaphor in multimedia resource, while in this study, for the typical research object, we do not take metonymy much into account.

\section{Methodology}

Generally speaking, this study employs the combination of quantitative and qualitative research method, that is to say, it is a process setting from general hypothesis and analyzing with specific linguistic phenomena and adequate data collection from the multimodal corpus.

\subsection{Multimodal Corpus}

Multimodal corpus is the corpus in which texts, audio, static and dynamic image are in the integration process, and for users to retrieve and count. It helps to apply theoretical concepts systematically to one real-life studies, such as a daily conversation including two speakers, a conference, or a commercial. Different from the pure textual corpora, multimodal corpora can be represented in many ways, and there is not any standard or widely used pattern.

Obviously, current studies on multimodal metaphors have not deepened into exploring a large-scaled corpus of advertisements and making some certain conclusions yet. The usage of corpus still concentrates on text corpus, such as the study "Cutting across the senses: Imagery in winespeak and audiovisual promotion" [19], which is based on a corpus of 12000 wine tasting notes in professional journals. Moreover, many studies just provide analysis of one single or no more than ten pieces of advertisements. This, on the other hand, exposes the shortage of insufficient corpora in multimodality research, and calls for the usage of multimodal corpus.

Nowadays, research of multimodal metaphor in advertisements mostly focuses on one certain video stream or audio, such as the demonstration of the nonverbal and multimodal manifestations of metaphors and metonymies by taking shots on the video, while few research is built on the base of multimodal corpus, which is of retrieval capability and accurately represents details based on the time line.

The main technology tool applied in this study is the multimedia annotator ELAN, which is first of all a precondition of the following exploration. As a multimedia annotator software designed by TLA (The Language Archive), a unit of the Max Planck Institute for Psycholinguistics, ELAN is a professional tool for the creation of complex annotations on video and audio 
resources. With ELAN an unlimited number of annotations can be added to audio or video streams. As for this study, the quantitative methodology of multimedia corpus features clear accurate details and precise statistical annotation data in every mode of advertisements. As the definition of multimodal metaphor comes down to the mapping from the source domain to the target domain, ELAN helps find out the target domain and source domain, and how they are represented exclusively or predominantly in different modes.

\subsection{Knowledge Base -- From Metaphor to Multimodal Metaphor}

Metaphors, as Ungerer and Schimid [24] defined, is a process of mapping from one cognitive domain or conceptual domain to another, and can be used to conceptualize abstract categories. Source domain is the conceptual domain from which people draw metaphorical expressions while target domain is the conceptual domain that people try to understand. Mapping, refers to the correspondence between two sets. It ensures that each member in one set has a counterpart in the other set [25]. That is to say, people understand the meaning of target domain when they understand the meaning and experience the characteristics of the source domain. In the mapping process, the similarities between source domain and target domain are highlighted, forming special meaning structure. According to different source domains, Lakoff and Johnson [1] distinguished conceptual metaphor into three categories, namely structural metaphor, orientational metaphor, and ontological metaphor. Besides, conceptual metaphor features systematicity, ubiquity, as well as universality and nationality.

As Forceville [26] defined, "multimodal metaphor is a cognitive process in which two domains are represented in two different modes, are those metaphors whose target domain and source domain are rendered exclusively or predominantly in two different modes/modalities (the term "mode" and "modality" are currently both in use; it is unclear at present which one will catch on)". A mode is a sign system interpretable because of a specific perception process, and with no obstacle there are nine modes: (1) pictorial signs; (2) written signs; (3) spoken signs; (4) gestures; (5) sounds; (6) music; (7) smells; (8) tastes; (9) touch.

Since multimodal metaphor is different from purely verbal metaphor, it has its own features: dynamics and narrativity, originality and creativity, and concreteness in metaphorical mapping. Forceville [26] claimed that the formula of verbal metaphor "A IS B" diminishes the nature of dynamic construction of metaphors. While different from highly abstract verbal signs, non-verbal metaphor usually shows features of high temporal and spatial sequence, or can build a concrete metaphorical scene by visual extension. A metaphor can conceptualize the concrete in terms of the concrete, while in multimodal metaphor, there are more representations which is concrete in terms of concrete, and many pictorial and multimodal metaphors are of the OBJECT A IS OBJECT B type.

Compared with pure verbal metaphor, the visual images and spatial dimension of source domain in multimodal metaphor are more concrete, and it is easier to attract the viewers and stimulate emotional effects through concrete visual images. Meanwhile, multimodal metaphor can convey the views and emotion that verbal metaphor can not. The classical CMT claims that the mapping can only be conducted from concrete domain to abstract domain. However, a number of studies have proved that people can also experience one concrete thing in terms of another concrete thing, namely, both the source and target domains can serve as perceived objects.

Mode plays a significant role in the interpretation of multimodal metaphors. As Forceville [14] suggests, "clearly, which channel (s) of information (language, visuals, sound, and gestures, among others) are chosen to convey a metaphor is a central factor in how a metaphor is construed and interpreted". Strictly speaking, in ideal multimodal metaphors the target is represented in one mode, and the source is in another mode. According to Forceville [13], metaphor is divided into monomodal metaphor and multimodal metaphor. Monomodal metaphors are defined as "metaphors whose target and source are exclusively or predominantly rendered in one mode" [23]. However, in the real-world situation, target and source can be represented in many modes respectively. For instance, the target can be represented in sounds and visual modes simultaneously, so as the source domain.

For present purposes and particular properties of ecological educational advertisement, the modes to be taken into account are two or more of the following: (1) visual mode; (2) verbal language mode; (3) non-verbal language mode; (4) music mode. All images, including characters, objects, color, and shape belong to visual mode. Verbal language refers to characters' verbal lines or aside which are expressed through sound, while non-verbal language includes subtitles, texts, and instructions on screen. Moreover, music mode plays a significant role in increasing expression and emotion.

\section{Discussions on Multimodal Metaphors}

\subsection{Prominent Metaphors in Ecological Educational Advertisements}

\subsubsection{Ontological Metaphor--Personification}

The most ontological metaphors are those where the physical object is further specified as being a person [1]. They express experiences with nonhuman entities in terms of human motivations, characteristics, and activities.

One of the main metaphors is NATURE IS A PERSON. The word "protect" in "We Should Protect the Environment" is a mapping of the source domain to the target.

In Figure 1, the little boy says: "There is also a panda eating old clothes." Obviously, here the "panda", which is actually a dustbin recycling old clothes, is personified and given human actions. But the metaphor is not merely RECYCLING DUSTBIN IS A PERSON, it is much more 
specific in the context, RECYCLING DUSTBIN IS A CLEANER.

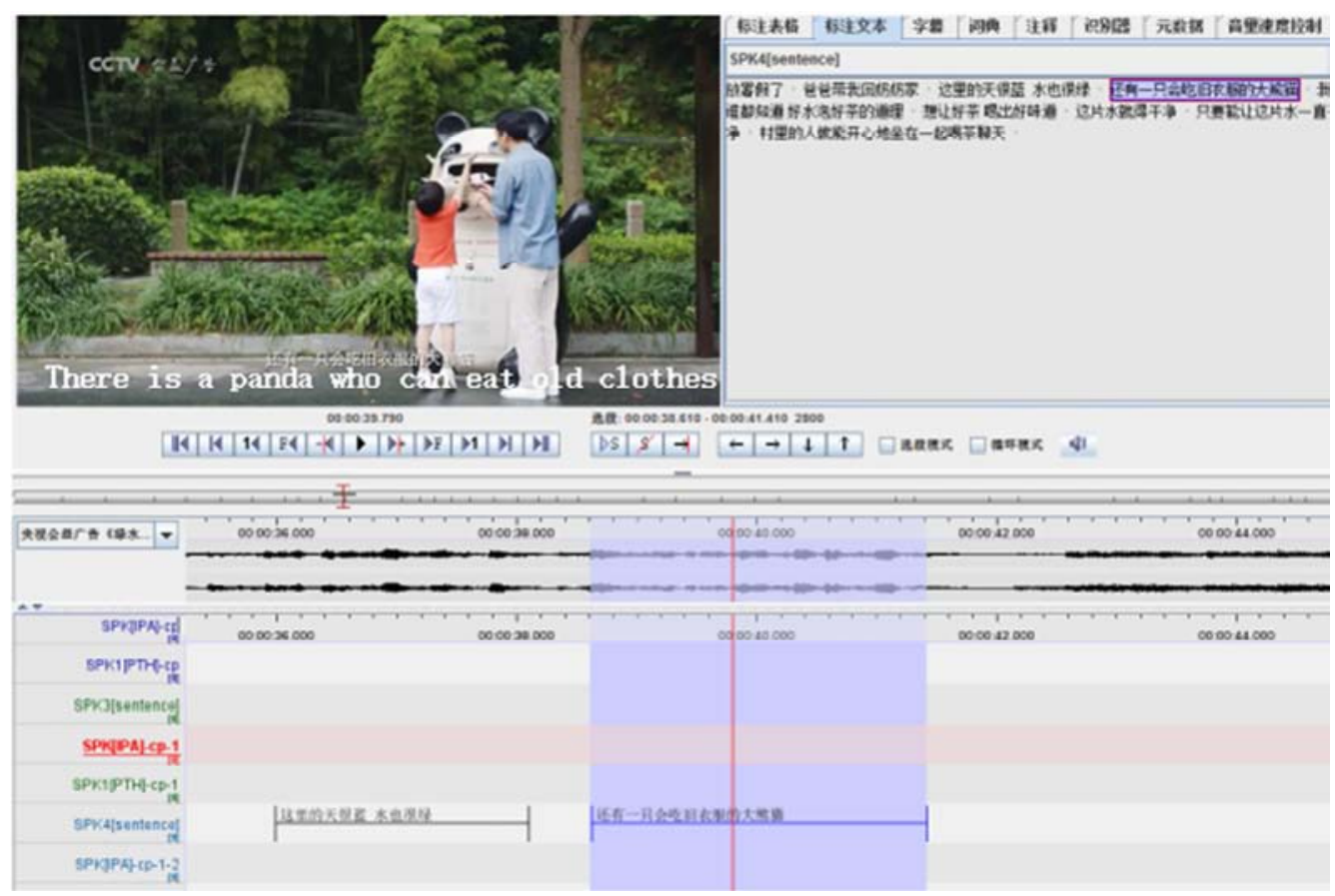

Figure 1. A screenshot of "Lucid water and fresh mountains".

The second example is "ELECTRIC APPLIANCE IS A PERSON". In the advertisement "Save Electricity", one of the written language "but they have not slept yet" is realized in nonverbal mode, in which this metaphor is represented prominently. Meanwhile, as Figure 2 shows, visual mode represents that background is screened as dark night house, and music mode plays slow background music, implying a sleeping environment.

Personification is a general category that covers a very wide range of metaphors, each picking out different aspects of a person or ways of looking at a person. Viewing something as abstract as electric appliance and dustbin in human terms has an explanatory power that makes sense to most people.

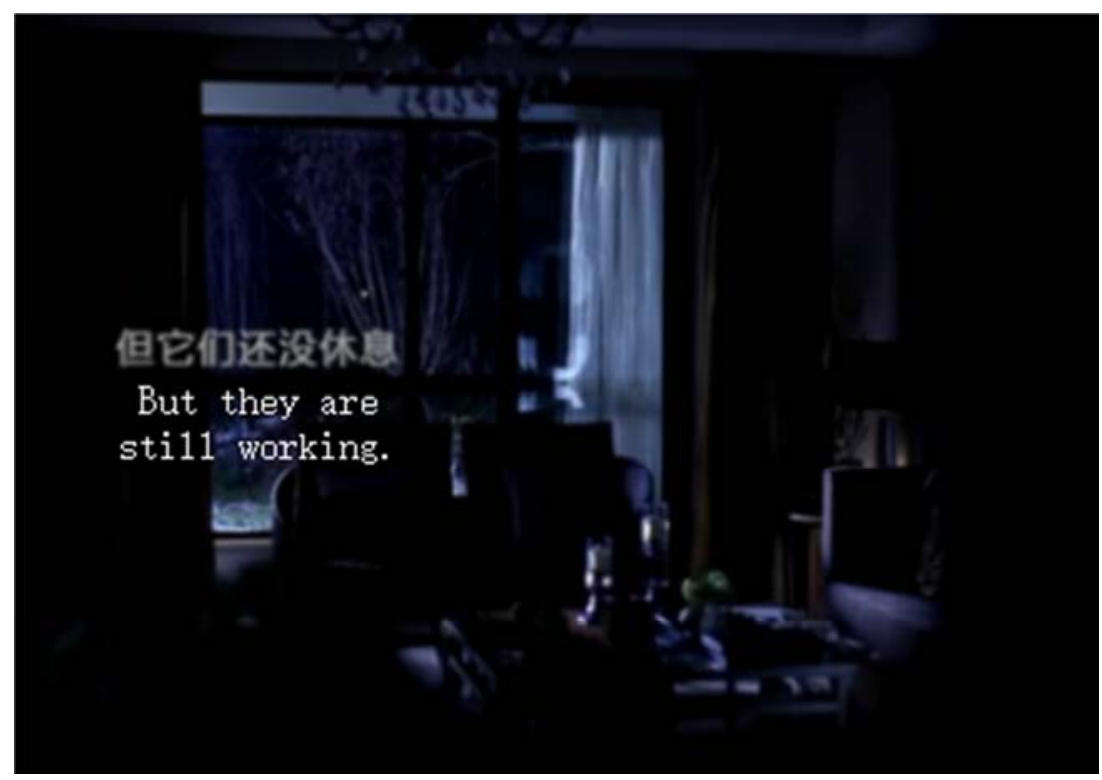

Figure 2. A screenshot of "Save Electricity".

\subsubsection{Color Metaphor}

In ecological educational advertisements, color green and blue are frequently represented and mapped into ecological items. These two colors are basically grounded in human experience that trees are green and the sky is blue, and this experience can be expressed in ecological educational advertisements that green and blue are positive ecological color, while gray and black are negative, suggesting deteriorating environment. 


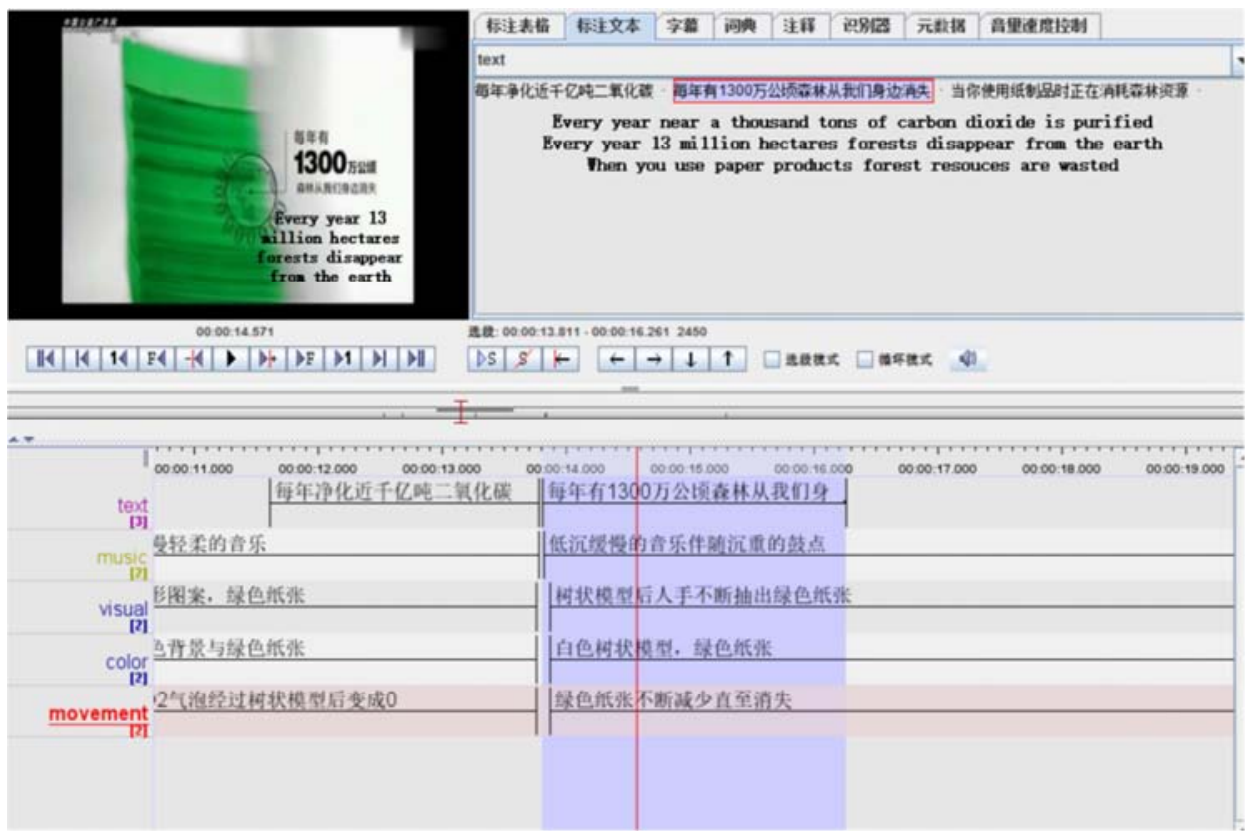

Figure 3. A screenshot of "Saving Paper".

Take the Figure 3 as an example, as the text "Every year 13 million hectares forests disappear from the earth" appears, green papers reduce as time goes by. This video piece represents the color metaphor mainly in visual mode, in which the source domain, green paper, is mapped into target domain, green trees. What is worth mentioning is that visual mode could be divided into several submodes, such as color and movement. In this metaphor, the green papers are representations of forests, while the reducing movement of papers represents the reduction of forests.

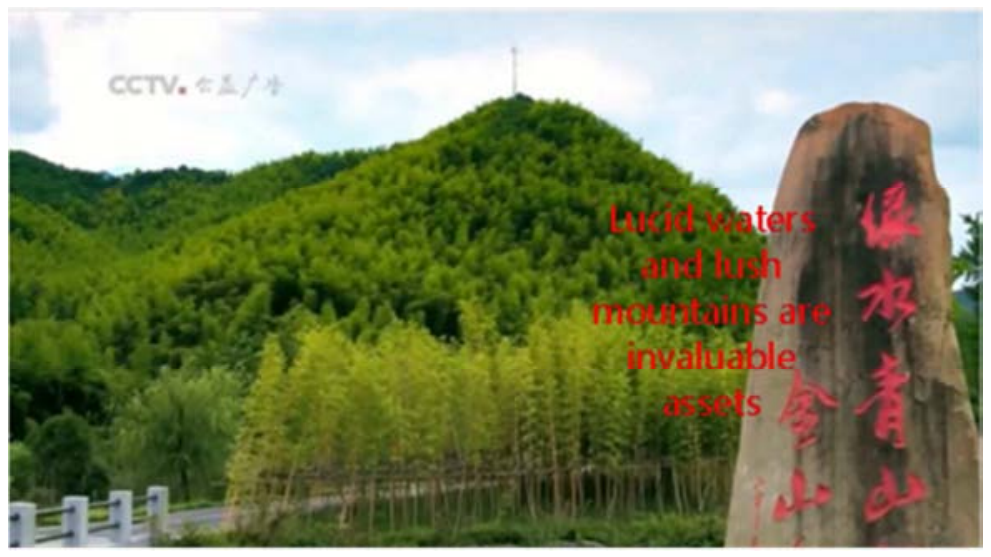

Figure 4. A screenshot of "Lucid Waters and Lush Mountains".

The theme "Lucid waters and lush mountains are invaluable assets"(in Chinese Pinyin "lù̀ shuǐ qīng shān jiù shì jīn shān yín shān") in piece "Lucid waters and lush mountains" is a color metaphor itself. This theme contains a color metaphor. In its Chinese version "lucid" is equal to green color, and the source domain is mapped into the target domain, good environment. From another aspect, this metaphor is an expansion of color metaphors. In this metaphor, the verbal message "lucid waters and lush mountains are invaluable assets", is only displayed on the screen with the lucid river around and lush mountains behind. Mappings of "lucid and lush" to "invaluable assets" are of art feeling. This message is very schematic, seen in Figure 4, with all the details furnished in the visual mode by concrete equivalent visual images, and it is coherent with the visual image.

In Figure 5 the girl dances to look for her boyfriend, but she is trapped by heavy haze. For her, looking for him is dancing a painful disoriented modern dance that she suffers. For her, the path of seeking lover runs from every corner of the city to the top of a skyscraper. Moreover, that is a path of going out from serious air pollution. Here, the color metaphor that BLUE IS GOOD ENVIRONMENT and GRAY IS BAD ENVIRONMENT is represented in visual mode and written language simultaneously, and both of them create mappings from the source domain of the gray city to the target domain of depressing life. 


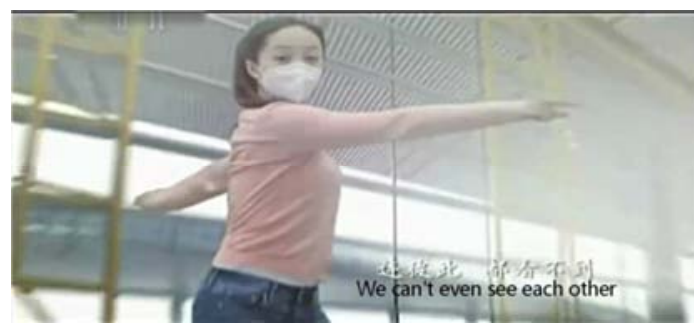

Figure 5. A screenshot of "Let's Make the Sky Blue".

Metaphorically, moreover, the physical perception of seeing is mapped onto the mental function of understanding in the primary conceptual metaphor UNDERSTANDING IS SEEING, as the lovers arrive at the top of the skyscraper, the view gets bright and clear, the levels of environment protection and air quality also improve.

\subsubsection{Good Environment Is Fortune}

The metaphor GOOD ENVIRONMENT IS FORTUNE plays an essential role in ecological educational advertisements. This metaphor creates mappings from the source domain of the fortune to the target domain of good environment and establishes correspondences between various items within these two conceptual domains, such as the following shown:

$\begin{array}{lll}\text { GOOD ENVIRONMENT IS FORTUNE: } \\ \text { SOURCE } & \rightarrow & \text { TARGET } \\ \text { GOOD ENVIRONMENT } & \rightarrow & \text { FORTUNE } \\ \text { RESOURCES } & \rightarrow & \text { MONEY } \\ \text { FORESTS } & \rightarrow & \text { ASSETS } \\ \text { SAVING RESOURCES } & \rightarrow & \text { VIRTUOUS }\end{array}$

Here comes the account of culture. Take the text "Lucid waters and lush mountains are invaluable assets", literally translated as "green water and mountains are gold and silver", for instance, in Chinese cultural context "jīnn"(gold) and "yín"(silver) are representatives of fortune, so the mappings are naturally built up and the metaphor is understood.

To cherish energy, to save resources, electricity, coal, water, and fuel, are common slogans appearing in educational advertisements. In these mappings meaning is created among messages mainly with the visual and verbal modes in assistance.

\subsubsection{Big Is Significant}

In the screenshot of "Save food, fight against waste" as Figure 6, the text "Every year, 1/3 of global total amount of food is wasted", the " $1 / 3$ " is magnified, thus the number " $1 / 3$ " is highlighted. This is the visual manifestation of a primary conceptual metaphor BIG IS SIGNIFICANT, i.e., BIGGER IS MORE SIGNIFICANT, which is combined with the image "vanished $1 / 3$ of the hamburger". This metaphor, of course, includes a multimodal metonymy "PART FOR WHOLE", i.e., the "hamburger" is a part of "food". In this metaphor, the background music mode cooperates with the image and written language, emphasizing the emergent mood.

This metaphor takes place in collaborations of visual and non-verbal modes. In visual mode, the source domain--"something significant" is highlighted larger in size or prominent in color, while in non-verbal mode, text makes implications or supplementary instructions to the visual mode.

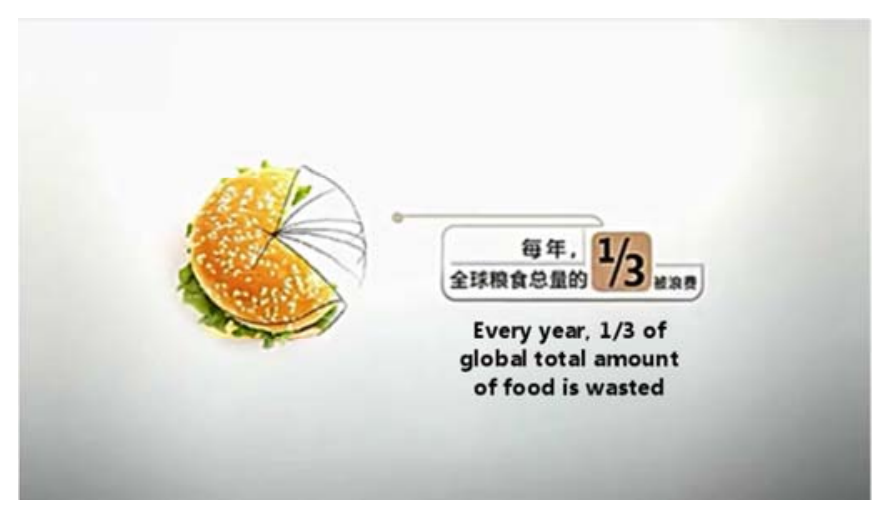

Figure 6. A screenshot of "Save Food, against Wasting".

As a matter of fact, there is overlap between the two different metaphors discussed, BIG IS IMPORTANT and RESOURCE IS MONEY. It is concluded that with the cooperation of different modes, different metaphors can be represented at the same time or successively.

\subsection{Collaborations of Modes in Multimodal Metaphors}

Following discussions on main multimodal metaphors, it is noticed that construction and meaning conveying of multimodal metaphors comes from collaborations of various modes. However, the process of creating metaphor does not only take place in multi-mode way, but also in mono-mode basically. In ecological educational advertisements, monomodal metaphor mostly takes place in non-verbal language mode, for instance, the text "Lucid waters and lush mountains are invaluable assets" is a metaphor itself. For present purpose, this part concentrates on collaborations of various modes in one certain multimodal metaphor.

In this study, modes are divided into visual, non-verbal and verbal language, and music modes. Actually, in addition to these primary modes, there still exist submodes under these five modes in the sense of category. Submodes can consist of different elements. For instance, in metaphor GREEN IS GOOD ENVIRONMENT, in its visual mode there may exist green color, movement of reducing green paper, and tree-shaped hollowed paperboard simultaneously.

\subsubsection{Simultaneous Collaboration}

Simultaneous presentation is the most fundamental way of presenting multimodal metaphors. Various modes, representing various representations in source or target domain of a metaphor, function at the same time. and thus construct meaning. It is suggested that modes embrace one mode, mostly the visual one. But sometimes there exists a short interval.

As a matter of fact, hidden hierarchical relations lie behind the four primary modes. For example, the visual mode could 
be divided into several submodes, such as color and movement. As it is showed in Table 1, submodes are building blocks of each mode. The movement of the reducing green paper actually acts out the reduction of the forest. Green color makes similarity both in paper and forest, reminding audience of green forests rapidly disappearing. The hue and colors are stereotypically ecological and thus present the feeling of urgency of protecting environment and associate to the metaphor GREEN IS TREE, thus, to the metaphor COLOR IS NATURE which can be found in the context of emotional relationships, and if that is the case, the color submode would integrate experiences of nature and emotion with the advertisement.

Table 1. Modes of metaphor in "Saving paper".

\begin{tabular}{llll}
\hline figure & components & Visual & non-verbal language \\
\cline { 2 - 4 } Metaphor & Reduction of forest & music \\
& SOURCE & Submode 1: Tree-shaped hollowed paperboard & $\begin{array}{l}\text { There 13 million hectares } \\
\text { forest disappearing every year }\end{array}$ \\
& & $\begin{array}{l}\text { Submode 2: Movement of the reducing green paper } \\
\text { with heavy drum beats }\end{array}$ & \\
& Submode 3: Green color & \\
\hline
\end{tabular}

\subsubsection{Differentiation Between Priority and the Others}

In collaborations of modes in multimodal metaphors, there exists differentiation between priority and the others in various modes. Generally speaking, representations of the source domain serve the target domain, and usually the visual mode is embraced as the core of meaning by the others.

Every mode performs its duty in multimodal metaphor. To be concise and to the key point, non-verbal language mode always concludes, highlights the theme, or make supplementary instruction. In the advertisement "Water Pollution-Nuclear Bomb Pollution", a drop of black water dropped into a glass of pure water, the black drop turned into nuclear-explosion-like shape, and the pure water turned into polluted water at last, at this moment, a piece of non-verbal language is screened as "even little pollution could lead to tremendous devastation" (in Chinese Pinyin "zài xiăo de wū răn yě huì zào chéng dà zāi nàn"), pointing out the theme and making it sublimated.

The differentiation between priority and the others depends on how much information a mode bears and conveys. The mode which carries the most information plays a central role in a multimodal metaphor. In almost all situations, the music mode functions to heighten emergent atmosphere as an assistant to the visual mode, non-verbal and nonverbal language modes serve more as supplementary instruction to the visual mode. Through Table 1 . showed above, it is explicitly concluded that in the ecological educational advertisements, it is the visual mode that acts as the priority, and other modes, sounds, non-verbal language, and verbal language act as assistants. This is because the nature of TV advertising lies in conveying information and making mono-directional communication by visual mode, which is the most efficient way.

In conclusion, multimodal metaphor is elaborated through a complex co-relation and co-operation of model techniques. Each mode and submode associates the product with the main metaphor, and relates it to sensations of urgency and heaviness of protecting environment. In this process, embraced by the others, some mode functions as the core, and its primary position is determined by the information it carries.

\subsection{Meaning Creation in Multimodality}

A crucial presupposition in advertisements is that a positive claim is made about the product advertised, so as in Chinese ecological educational advertisements. In these advertisements, the central purpose is appealing for environmental protection to every single person, which should be embraced in the whole process of advertising. Setting from this aim, ecological advertisements deploy and coordinate all modes, image, text, music, non-verbal and verbal language included, to express its central meaning.

According to Lakoff and Johnson [1], "the essence of metaphor is understanding and experiencing one kind of thing in terms of another", and the key to the construction of multimodal metaphor is the similarity of target and source domain. However, in multimodal metaphors the signals that cue metaphorical similarity between two phenomena are different, and the signals are bound to differ depending on the modes in which the metaphorical terms are represented. Since nonverbal modes of communicating by definition do not have the "is" or "is like", in order to signal a metaphorical identity relation between two entities, one issue that deserves attention is what stylistic means triggers the similarity. As Forceville [23] summarizes, perceptual resemblance, filling a schematic slot unexpectedly, and simultaneous cueing are three representations of similarity in multimodal metaphor.

Taking into account the particular researching object, the meaning-creating role of advertising and the limitation of testing audiences' understanding process, this study places emphasis on the construction of similarities between target and source domain. In ecological educational advertisements, particularly, there exist two main possibilities, in which modes are deployed isolated or combined.

\subsubsection{Simultaneous Cueing}

The most frequent presentation in ecological educational advertisements is simultaneousness, i.e., various modes collaborate at the same time to construct a multimodal metaphor. If two things are signaled in different modes, metaphorical identification is achieved by saliently representing target and source simultaneously. 
In ecological educational advertisements, non-verbal and image modes act as main meaning-creating modes, while music and verbal language modes function as assistants to strengthen meaning. Although there exists differentiation between priority and the others in modes, there is no differentiation in timeline, i.e., they collaborate at the same time. Every representation of a certain mode will come onto screen at an appropriate time. It is possible that between two modes there exists interval, but in this study, the tiny time lag is not taken into account. For instance, in the advertisement "Save Food", a barrel of swill could be accompanied by the tic - toc sound of watch, or the sound of counting down, to cue metaphorical mappings of disaster and dreary urgency. Alternatively, in a variant on the previous mechanism, two disparate things can be linked because of an unexpected filling of a slot, as when a photograph of waste food has the caption "death and pollution".

\subsubsection{Perceptual Resemblance}

Perceptual resemblance refers to the resemblance experienced through visual perception or auditory sense. A visual representation can perceptually resemble another visual representation and a sound can perceptually resemble another sound in volume, timbre, or pitch. In multimodal metaphor, what is triggered the most is visual resemblance, which means two entities can resemble one another because they have the same size, color, position, posture, texture, materiality, etc.

Similarity of the shape of objects to target domain takes place most commonly in visual mode. In the piece "Water-pollution of Nuclear Bomb", the mushroom-cloud-shape polluted water represented in visual mode indicates the pollution caused by nuclear. For the profound impression in human minds as mushroom cloud image, nuclear bomb is abstracted into mushroom-cloud-shape polluted water by visual resemblance.

Perceptual resemblance is perceived in music mode all the time. The urgency of protecting environment is highlighted by the fast tempo of background music, and the heavy mood of facing the deteriorated environment is equipped with heavy drums. Through perceptual resemblance the intention of educational advertisement is strengthened and conveyed effectively.

\subsubsection{From the Perspective of Audience's Understanding}

As a conceptual way, the understanding of multimodal metaphor is undergone in mind, similarly, the meaning creation should be viewed from the perspective of audiences' mind. Because of the complexity of human mind, this study does not take much of physiological mechanism into consideration, but the already known conceptual mechanisms The closer a metaphor is to human embodied experience, the easier it is for audience to understand and get impressed. Actually, human body experience exerts influence on understanding metaphors in ecological educational advertisements, and consequently influences the formation of concepts as well as the way of expressing in language, such as color, feelings of anger, and gestures. Body experience plays a significant role in both the choice of visuals, language, hearings in the advertisements and understanding of meanings in ecological educational advertisements.

The process of understanding multimodal metaphor can be named decoding. In these ecological educational advertisements, visual information is decoded by the perceptual mode, these mental modes get activated automatically when the appropriate type of input reaches them, and both yield de-contextualized pieces of evidence of the sender's intention to communicate some information. This context-free information is then enriched inferentially in order to obtain a fully satisfactory (i.e., relevant) interpretation of the verbal or visual input. And the process of meaning creation exactly happens at the same time of the appropriate input.

To conclude the meaning creating of multimodal metaphor, in a multimodal text, meaning is created through visuals, language, music and the combination of the three in order to achieve effects and meanings that would not be possible in either a strictly print or strictly visual text. That is to say, meaning of multimodal metaphor can be perceived only in multimodal way, any loss of mode could be impeditive elements in the understanding process of audience.

\section{Conclusion}

In this particular multimodal corpus, prominent metaphors include personification as NATURE IS A PERSON, money metaphor as GOOD ENVIRONMENT IS FORTUNE, color metaphors such as BLUE IS GOOD and GRAY IS BAD, and BIG IS SIGNIFICANT. These metaphors highlight characteristics of ecological educational advertisements, and map the source domain to the target domain by means of collaboration of different modes.

Meaning of multimodal metaphor can be perceived only in multimodal way, and any loss of mode could be impeditive elements in understanding process. All multimodal metaphors in ecological educational advertisements are represented in combinatorial visual, non-verbal, verbal language, and music modes, among which visual mode acts as the main meaning-creating mode, while verbal or nonverbal message, music, and other modes always act as assistant modes. This is differentiation between prior mode and the others, which is determined by the information it carries. By means of simultaneous collaborations, modes contribute to the central theme of the ecological TV educational advertisements that induce people to protect the environment.

Meaning creation comes from not only collaborations of modes, but also perceptual resemblance and simultaneous cueing. The resemblance experienced through visual perception or auditory sense triggers similarity of the source and the target domain, and thus constructs a multimodal metaphor. In this particular type of advertisement, similarity in the shape of objects takes place the most in visual mode.

It's worth mentioning that visual information is decoded by the perceptual mode. These mental modes get activated automatically when the appropriate type of input reaches them, and both yield de-contextualized pieces of evidence of the sender's intention to communicate some information. 
This context-free information is then enriched inferentially in order to obtain a fully satisfactory (i.e., relevant) interpretation of the verbal or visual input.

As it is shown, scholars can seek multimodal laws by building an aimed corpus and making more detailed interpretation. However, there still remain questions, like whether the usage of multimodal corpus can be applied in all multimodal research or even in language universals, and it needs more discussion on the details of building a corpus.

For further studies, deeper exploration in theories of multimodal metaphor is expected, and it is hoped that research of multimodality may collect more resources and conclude universal rules. Moreover, it is promising to verify the validity of these conclusions in future studies, and it is necessary to explore the universal rule behind the surface metaphorical phenomenon with quantitative methodology.

\section{References}

[1] Lakoff, G. \& Johnson, M. (2003). Metaphors we live by. Chicago / London: University of Chicago Press.

[2] O'Toole, M. (1994). The language of displayed art. London: Leicester University Press.

[3] Kress, G. \& Van Leeuwen, T. (1996). Reading images. London: Routledge.

[4] Baldry, A. P. \& Thibault P. J. (2006). Multimodal transcription and text. London: Equinox.

[5] Bateman, J. (2008). Multimodality and genre: A foundation for the systematic analysis of multimodal documents. Basingstoke: Palgrave Macmillan.

[6] Kress, G. \& Van Leeuwen, T. (2001). Multimodal discourse: The modes and media of contemporary communication. London: Arnold Publishers.

[7] Kress, G. et al. (2001). Multimodal teaching and learning: The rhetorics of the science classroom. London: Continuum.

[8] O'Halloran, K. L. (2004). Multimodal discourse analysis. London: Continuum.

[9] O'Halloran, K. L. (2005). Mathematical discourse: Language, symbolism and visual images. London: Continuum.

[10] O'Halloran, K. L. (2008). Systemic functional-multimodal discourse analysis (SF-MDA): constructing ideational meaning using language and visual imagery. Singapore: Visual Communication, 7 (4): 443-475.

[11] Bart, E. (2018). Anger in Asterix: The metaphorical representation of anger in comics and animated films. In C. Forceville \& E. Urios-Aparisi (eds.), Multimodal metaphor. pp. 243-264. Berlin/New York: Mouton de Gruyter.
[12] El Refaie, E. (2018). Metaphor in political cartoons: Exploring audience responses. In C. Forceville \& E. Urios-Aparisi (eds.), Multimodal metaphor. pp. 173-196. Berlin/New York: Mouton de Gruyter.

[13] Forceville, C. (1998). Pictorial metaphor in advertising. London/ New York: Routledge.

[14] Forceville, C. (2007). Multimodal metaphor in ten Dutch TV commercials. Public Journal of Semiotics, 1 (1): 19-51.

[15] Koller, V. (2018). Brand images: Multimodal metaphor in corporate branding messages. In $\mathrm{C}$. Forceville \& E. Urios-Aparisi (eds.), Multimodal metaphor. pp. 45-72. Berlin/New York: Mouton de Gruyter.

[16] Norman, T. Y. (2018). Image alignment in multimodal metaphor. In C. Forceville \& E. Urios-Aparisi (eds.), Multimodal metaphor. pp. 197-212. Berlin/New York: Mouton de Gruyter.

[17] Rohdin. M. (2018). Multimodal metaphor in classical film theory from the 1920 s to the 1950s. In C. Forceville \& E. Urios-Aparisi (eds.), Multimodal metaphor. pp. 403-428. Berlin/New York: Mouton de Gruyter.

[18] Zbikowski. L. M. (2018). Music, language, and multimodal metaphor. In C. Forceville \& E. Urios-Aparisi (eds.), Multimodal metaphor. pp. 359-382. Berlin/New York: Mouton de Gruyter.

[19] Caballero, R. (2018). Cutting across the senses: Imagery in winespeak and audiovisual promotion. In C. Forceville \& E. Urios-Aparisi (eds.), Multimodal metaphor. pp. 73-94. Berlin/New York: Mouton de Gruyter.

[20] Forceville, C. (1994). Pictorial metaphor in advertisements. Metaphor and Symbolic Activity. 9. 1-29.

[21] McQuarrie, E. F. \& Phillips, B. J. (2005). Indirect persuasion in advertising: How consumers process metaphors in pictures and words. Journal of Advertising, 34 (2): 7-20.

[22] Forceville, C. (2006). Non-verbal and multimodal metaphor in a cognitivist framework: Agendas for research. In G. Kristiansen et al. (eds.), Cognitive linguistics: Current Applications and future perspectives. pp. 379-402. Berlin: Mouton de Gruyter.

[23] Urios-Aparisi, E. (2018). Interaction of multimodal metaphor and metonymy in TV commercials: Four case studies. In C. Forceville \& E. Urios-Aparisi (eds.), Multimodal metaphor. pp. 95-117. Berlin/New York: Mouton de Gruyter.

[24] Ungerer, F. \& Schmid, H. J. (2013). An introduction to cognitive linguistics. Routledge.

[25] Fauconnier, G. (1997). Mappings in thought and language. Cambridge University Press.

[26] Forceville, C. (2018). Non-verbal and multimodal metaphor in a cognitivist framework: Agendas for research. In C. Forceville \& E. Urios-Aparisi (eds.), Multimodal metaphor. pp. 19-42. Berlin/New York: Mouton de Gruyter. 